\title{
Crisis del Estado de Bienestar y desafíos del siglo xxI: dualismo vital y brecha ciudadana*
}

Juana María Gil Ruiz

DOI: https://doi.org/10.47623/ivap-rvap.109.2017.1.04

\begin{abstract}
Sumario: I. Un paseo por el derecho.-II. Diagnóstico de la posición de las mujeres en la esfera laboral.-III. Austeridad y pacto europeo por la igualdad de género: áreas de intervención. 1. Desempleo y pobreza. 2. Trabajo de cuidados y conciliación. 3. Violencia de género en el contexto de pareja.-IV. Algunas propuestas concluyentes y de mejora. $-V$. Bibliografía.
\end{abstract}

\section{Un paseo por el derecho}

Nos encontramos inmersos en un proceso de plena ebullición social, política y mediática que reclama cambios jurídicos a corto plazo con el ánimo de erradicar las distintas formas de violencia de género y acortar la significativa brecha de disfrute de derechos ciudadanos entre hombres y mujeres. En este sentido, tanto a nivel nacional como autonómico, algunas voces apelan a la urgencia de cambio y anotan en sus agendas modificaciones inminentes al respecto de la reciente apuesta legislativa que, por otra parte, España lleva haciendo apenas unos años atrás. La L.O.3/2007, de 22 de marzo para la Igualdad Efectiva de Mujeres y Hombres acaba de cumplir diez raquíticos años, y la L.0. 1/2004, de 28 de diciembre de Medidas de Protección Integral contra la violencia de Género (por cierto, recientemente modificada en su artículo 1), pre-adolescente, no llega ni a los trece. En algunas comunidades autónomas, como Andalucía, se anuncia que a inicios de 2018 se presentará el Proyecto de Reforma de la Ley para la Promoción de la Igualdad de Género en Andalucía (Ley 12/2007, de 26 de noviembre), erigiéndose en la primera ley que se apruebe por el Parlamento Andaluz a la vuelta de año.

\footnotetext{
* Este trabajo se inscribe en el marco del Proyecto I+D+i del Ministerio de Economía y Competitividad Carencias y alternativas jurídico-políticas al tratamiento de las violencias de género: formación e investigación en Derecho Antidiscriminatorio, DER 2014-57244-R. Responsable principal: Juana María Gil Ruiz.
} 
Sin embargo, tanto anuncio de modificación legislativa requiere, entiendo, tener conocimiento de lo conseguido y de donde nos encontramos jurídica y políticamente hablando. Hallar la puerta de salida en una habitación oscura, reclama ante todo, tomar conciencia de la posición que ocupamos en la misma para dirigirnos - con los menos golpes posibles y de manera certera y firme - hacia el exit para la igualdad efectiva ciudadana. $Y$ esto requiere, al menos, reparar en algunos de estos avances jurídicos conseguidos, con no poco esfuerzo, recuperar a sus protagonistas y la metodología desde donde afrontarla y blindar la infraestructura de género que apenas acaba de llegar (que no penetrar) en las estructuras del sistema jurídico y político. Y esto implica: tiempo, conocimiento, reflexión y sobre todo, puesta en marcha -acción- de muchos de los mecanismos ya arbitrados para la consecución de los objetivos de igualdad, pero que esperan la llegada de un mayor compromiso político, de recurso humano más preparado y, sobre todo, de formación en género para poderlo acometer con rigor. Dicho esto, resulta obligado, aunque solo sea brevemente, hacer un breve paseo por el Derecho, y enmarcar los cambios legislativos desde la Constitución hasta nuestros días, en lo que debiera ser un nuevo marco jurídico antisubordiscriminatorio (Gil Ruiz, 2017), que debería hacer convulsionar las estructuras del sistema patriarcal excluyente para una buena parte de la ciudadanía. Sin duda hablamos de retos del siglo XXI, y esto implica partir del conflicto de Género, desde el conocimiento y el compromiso.

El 27 de diciembre de 1978, la Constitución española abrió la puerta formal de la igualdad con un novedoso y deseado artículo 14 que proclamaba que "Los españoles son iguales ante la ley, sin que pueda prevalecer discriminación alguna por razón de nacimiento, raza, sexo, religión, opinión o cualquier otra condición o circunstancia personal o social». Probablemente consciente de que un mero principio programático no iba a generar de manera automática la tan anhelada igualdad real, el legislativo constitucional compromete -en el artículo 9.2 C.E. - a los poderes públicos en la lucha por promover las condiciones para que la libertad y la igualdad del individuo y de los grupos en que se integra sean reales y efectivas; en remover los obstáculos que impidan o dificulten su plenitud y facilitar la participación de todos los ciudadanos en la vida política, económica, cultural y social.

Asimismo, el artículo 35 de nuestra Carta Magna reza: «1. Todos los españoles tienen el deber de trabajar y el derecho al trabajo, a la libre elección de profesión y oficio, a la promoción a través del trabajo y a una remuneración suficiente para satisfacer sus necesidades y las de su familia, sin que en ningún caso pueda hacerse discriminación por razón de sexo. 2. La ley regulará un estatuto de trabajadores». 
Han pasado 39 años de aquella victoria en pro de la libertad y de la igualdad, y la pregunta que nos seguimos planteando es si realmente dicha proclama del artículo 14 se presenta en la actualidad con entidad real desde una perspectiva de género o si, por el contrario, continúa formando parte de las entelequias o de los buenos deseos políticos de un Estado que se califica de Democrático y Social de Derecho. No queremos con esto desmerecer los importantes esfuerzos que se han hecho a nivel jurídico de adecuación de la legislación al principio de no discriminación señalado por la Constitución de 1978 y por la normativa comunitaria, todo lo contrario, pero entendemos que ni la igualdad legal-formal entre hombres y mujeres es suficiente, requiriendo medidas de carácter compensatorio, ni la falacia del igualitarismo jurídico puede llevarnos a «deponer las armas» en la lucha por la igualdad real. No en vano, el Pacto Europeo por la Igualdad de Género (2011-2020), en el contexto de la Estrategia 2020, insiste en tres objetivos más que recurrentes en lo que a las deficiencias de igualdad efectiva ciudadana se refiere; a saber: reducir las desigualdades en cuanto al empleo y protección social; promover un mejor equilibrio entra la vida laboral y privada de mujeres y hombres; y combatir todas las formas de violencia contra las mujeres.

Desde entonces hasta ahora se han modificado leyes, se han puesto en marcha acciones positivas diferenciadoras que pretenden nivelar desigualdades, y se han propuesto medidas - con mayor o menor éxitocon el objetivo de garantizar la igualdad de oportunidades en el empleo, facilitar la conciliación de la vida laboral y familiar - no tanto la personal-, impulsar la participación de las mujeres o combatir la execrable lacra social que es la violencia de género. Sin duda alguna, la aprobación unánime por todas las fuerzas políticas de la L.O.3/2007, de 22 de marzo para la igualdad efectiva de mujeres y hombres inaugura un antes y un después en el hacer jurídico y político en torno a la igualdad ciudadana (Gil Ruiz, 2012).

No obstante, y aun cuando escuchemos que la situación de las mujeres ha cambiado sustancialmente en las últimas décadas, en España todavía persiste un importante nivel de desigualdad que pone en entredicho los valores que fundamentan el orden democrático. He aquí algunos datos, a modo de sumario, que constatan dicha aseveración: la participación política de las mujeres, teniendo en cuenta todos los órganos de decisión, se mantiene con índices inferiores a los recomendados por la Unión Europea. El salario medio que perciben las mujeres es inferior al salario medio que perciben los hombres. Las mujeres soportan frecuentemente la acumulación de su jornada laboral al trabajo doméstico no remunerado, y éste es mayoritariamente la única actividad que desempeñan. En el caso de las familias monoparentales, éstas tienen generalmente como cabeza de familia a las madres, que a su vez represen- 
tan el porcentaje más alto de parados en esta situación. Las mujeres son las principales beneficiarias de pensiones asistenciales o de viudedad que son las económicamente más bajas.

La necesidad de eliminar las diferencias existentes entre mujeres y hombres requiere la adopción de medidas urgentes que, partiendo de los desequilibrios que caracterizan las actuales relaciones de género, se encaminen a la superación de la discriminación por razón de sexo tanto desde una perspectiva individual como colectiva, con la finalidad de garantizar el derecho fundamental a la igualdad entre mujeres y hombres(1).

Una mirada al "deber hacer» jurídico-político europeo nos remonta - paradójicamente - a 1992, cuando la Recomendación del Consejo de la CEE, 92/442/CEE de 27 de julio de 1992 de convergencia de los objetivos y políticas de protección social(2), recomienda a los Estados miembros «contribuir a suprimir los obstáculos al ejercicio de una actividad profesional por parte de los padres con medidas que permitan conciliar las responsabilidades familiares y la vida profesional». La necesidad de conciliar la vida familiar y laboral debe percibirse como una condición vinculada de forma inequívoca a la realidad social. De hecho, ya a nivel internacional, la IV Conferencia Mundial sobre las mujeres celebrada en Pekín, en septiembre de 1995, tras recordarnos que los derechos de las mujeres son derechos humanos, lo consideró objetivo estratégico y fue ratificado, con un compromiso formal, por los 189 Estados allí reunidos. Textualmente: "La igualdad de derechos, de oportunidades y de acceso a los recursos, el reparto igualitario de las responsabilidades respecto de la familia y una relación armoniosa entre mujeres y hombres son indispensables, tanto para su bienestar y el de sus familias, como para la consolidación de la democracia» (3). Y toda esta proclama la inserta en un marco de incorporación del principio del gender mainstreaming, como principio vinculante al que deben dirigirse todas las medidas legislativas, y de acción política -que incluye programas y proyectos públicos-. Este principio también fue incorporado por la Unión Europea en su acervo comunitario que reatraviesa desde el Tratado de Ámsterdam (art. 3.2), hasta el Tratado de Lisboa (art.8), sin olvidarnos de Directivas de significativo interés (4) al

(1) Véase la Estrategia 2020. Una estrategia para un crecimiento sostenible e integrador. Comunicación de la Comisión de Bruselas, 3.3.2010, COM (2010) 2020 final.

(2) Recomendación del Consejo 92/442/CEE, de 27 de julio de 1992, relativa a la convergencia de los objetivos y de las políticas de protección social, en D.O.C.E., n. ${ }^{\circ}$ L 245/49, 26 de agosto de 1992.

(3) IV Conferencia Mundial sobre las mujeres, Beijing, China, 4 a 15 de septiembre 1995, punto 15.

(4) La Directiva 2006/54, en su artículo 29 afirma: «Transversalidad de la perspectiva de género: Los Estados miembros tendrán en cuenta de manera activa el objetivo de la igualdad entre hombres y mujeres al elaborar y aplicar disposiciones legales, reglamentarias y administrativas, así como políticas y actividades, en los ámbitos contemplados en la presente Directiva». 
respecto, que obligaban a los Estados parte a transponer lo suscrito en tanto que objetivo prioritario de la Unión Europea. No en vano, se trata «de un principio firme y creciente, en el seno de la Unión Europea. En efecto, ha sido reconocido por el art. 3 del Tratado de Ámsterdam, (también en el art. 8 del Tratado de Lisboa), que ha incluido, como una de las prioridades a tener en cuenta en el diseño de Políticas Europeas, la promoción de la lgualdad de mujeres y hombres en todas las políticas y la eliminación de las discriminaciones. Se incluye como objetivo de la Unión, la promoción de la igualdad entre hombres y mujeres (hasta el punto de condicionar) el conjunto de las Políticas Comunitarias al objetivo de la consecución de esa igualdad" (Rey Martínez, 2004). Ello implica que el fin de la igualdad ciudadana no se alcanza a través de una o varias acciones específicas, sino integrándolo en todas las acciones y confirma el mayor rango de protección europeo por razón de género frente a otros cortes sistémicos. De este modo, y como puede constatarse en la redacción del artículo 157 del Tratado de Funcionamiento de la Unión Europea, "Cada Estado miembro garantizará..." - lo que implica intervención directa e incondicionada supra-estatal - cuando se trate de discriminaciones producidas por razón de género, frente al resto de causas de discriminación que también interseccionan y reatraviesan al género, pero que no configuran un derecho de eficacia directa por ahora(5). Frente a estas segundas - art. 19 TFUE - «(... El Consejo (...) podrá adoptar acciones adecuadas)". Asimismo, el ámbito material de protección dispensada se configura distinto para las primeras, más rico y abierto - tocante al ámbito laboral y al no laboral-, frente al resto de causas de discriminación prohibidas que poseen una protección limitada centrada en la esfera laboral (6).

Y no puede ser de otra forma siendo coherentes con el Tratado de la Unión (Lisboa, 2009) y con la Carta de los derechos fundamentales de la Unión Europea -que hace suya en su artículo 6.1- que establece (artículo 23 de la Carta) que la «igualdad entre mujeres y hombres deberá garantizarse en todos los ámbitos, inclusive en materia de empleo, trabajo y retribución» y que "el principio de igualdad no impide el mantenimiento o la adopción de medidas que supongan ventajas concretas a favor del sexo menos representado».

(5) Se puede detectar también un cierto mayor grado de protección en la discriminación por razón de etnia, con un ámbito material más abierto que incluye esfera laboral y extra-laboral. Véase la Directiva 2000/43 del Consejo, de 29 de junio de 2000, relativa a la aplicación del principio de igualdad de trato de las personas independientemente de su origen racial o étnico, DOUE, $n .^{\circ} 180$ de 19 de junio de 2000.

(6) Directiva 2000/78 del Consejo, de 27 de noviembre de 2000, relativa al establecimiento de un marco general para la igualdad de trato en el empleo y la ocupación, publicada en DOUEL, n. ${ }^{\circ} 303$, de 2 de diciembre de 2000. 
De este modo, en el ámbito comunitario, la maternidad y la paternidad han sido contempladas en dos Directivas del Consejo de significativo interés. Nos referimos a la Directiva 92/85/CEE, de 19 de octubre de 1992 que contempla la maternidad desde la perspectiva de la salud y la seguridad en el trabajo de la trabajadora embarazada, que haya dado a luz o que se halle en el período de lactancia (7); y la Directiva del Consejo 96/34/ CEE de 3 de junio de 1996, fruto de un acuerdo entre la UNICE, el Centro Europeo de la Empresa Pública y la Confederación Europea de Sindicatos, derogada por la Directiva 2010/18/UE del Consejo de 8 de marzo de 2010, que preveía el permiso parental como derecho individual e intransferible y la ausencia del trabajo por motivos de fuerza mayor. Se trataba originariamente, según calificó la Eurocámara de "un punto de partida fundamental» en la consecución de la igualdad de oportunidades y de trato entre hombres y mujeres, aun cuando se lamentaba de que su adopción hubiera sido a través de una directiva, y no como reglamento con aplicación inmediata. La actual Directiva 2010/18/UE aplica el acuerdo marco revisado, el 18 de junio de 2009, por las organizaciones europeas de interlocutores sociales intersectoriales, matizando e innovando algunos de sus términos. Entre ellos, repárese en la Cláusula 6 de la misma titulada "Reincorporación al trabajo», que introduce - aunque a título indicativo - ciertas prerrogativas del trabajador para adaptar su jornada de trabajo tras el disfrute de un permiso parental.

En esta línea de amplitud del ámbito material de protección antes señalado tampoco pueden desconocerse - centrada en el ámbito laboralla Directiva (de refundición) 2006/54/CE del Parlamento Europeo y del Consejo (8), de 5 de julio de 2006, relativa a la aplicación del principio de igualdad de oportunidades e igualdad de trato entre hombres y mujeres en asuntos de empleo y ocupación; como la Directiva 2004/113/CE sobre aplicación de la igualdad de trato entre hombres y mujeres en el acceso a bienes y servicios y su suministro, referida al ámbito extralaboral.

Asimismo, no debemos olvidar que esta necesidad de conciliar vida personal, familiar y laboral se encuentra enmarcada también dentro del Convenio 156 de 1981 (OIT) sobre personas trabajadoras con responsabilidades familiares, así como la Recomendación 165 (OIT); o en el enfoque

(7) En la actualidad esta regulación, superada por la OIT, pretende ser modificada por otra posterior pero aún no ha logrado ser aprobada.

(8) Esta Directiva refunde $-y$ sustituye desde el 15 de agosto de 2009-, a las Directivas 2002/73/ CE del Parlamento Europeo y del Consejo, de 23 de septiembre de 2002, que modifica la Directiva 76/207/CEE del Consejo relativa a la aplicación del principio de igualdad de trato entre hombres y mujeres en lo que se refiere al acceso al empleo; la Directiva 75/117/CEE relativa a la igual retribución, la 86/378/CEE sobre la igualdad de trato en regímenes profesionales de Seguridad Social (también modificada por la Directiva 96/97/CEE), y la 97/80/CEE, relativa a la carga de la prueba en los casos de discriminación por razón de sexo. 
socio-laboral del Convenio 183 de la OIT sobre protección de la maternidad (9) y de la Carta Social Europea incidiendo en la protección «especial» de las trabajadoras.

Dentro del marco jurídico nacional, la necesidad de conciliar vida - personal- familiar y laboral tiene como fundamento los artículos 9.2, 14 y 39 de la Constitución Española, que contemplan, respectivamente, la promoción de las condiciones para que la libertad e igualdad de las personas sean reales y efectivas, el principio de igualdad ante la ley y no discriminación y la protección social, económica y jurídica de la familia. De este modo la Ley 39/1999, de 9 de noviembre de 1999 de conciliación de la vida familiar y laboral de las personas trabajadoras estructurada en 22 artículos modificaba el Estatuto de los Trabajadores, la Ley de Procedimiento Laboral, la Ley de Prevención de Riesgos Laborales, la Ley General de la Seguridad Social, algunas Leyes reguladoras de la Función Pública, así como el Real Decreto Ley 11/1998, de 4 de septiembre, por el que se regulan las bonificaciones de cuotas de la Seguridad Social de los contratos de interinidad que se celebren con personas desempleadas para sustituir a trabajadores durante los periodos de descanso por maternidad, adopción o acogimiento.

Sin embargo, la Ley de Conciliación no ha conseguido - probablemente porque no miraba hacia la corresponsabilidad-, sino todo lo contrario, difuminar las enormes diferencias existentes entre los géneros en el acceso, promoción profesional y condiciones de trabajo. La ley ha resultado ser, paradójicamente, una invitación jurídica a que el empresariado no contrate a mujeres en tanto que arbitra, entre otros, permisos retribuidos (art. 37.3.b E.T.), reducciones de jornada (art. 37.4 .5 y 6 E.T) y períodos de excedencia (art. 46.3. E.T) ya no sólo para el cuidado y crianza de menores, sino para el cuidado de un familiar enfermo hasta un segundo grado de consanguinidad y/ o afinidad. Pese a que la Ley fue especialmente cuidadosa en el uso del lenguaje y en todo momento habla de "personas trabajadoras", los datos sociológicos vienen a constatar que quien, mayoritariamente, se ocupa de la "ética del cuidado" son las mujeres (10).

(9) No obstante, y pese a centrarse en el ámbito laboral, es importante destacar que el Convenio 183 de la OIT considera que la protección del embarazo es una responsabilidad compartida de gobierno y sociedad, conformado por cinco componentes: licencia de maternidad, protección del empleo, prestaciones dinerarias y médicas, protección de la salud (respecto a un trabajo perjudicial para la salud de la mujer o de la niña o niño) y lactancia. Véase también la Recomendación de la OIT 191 (adoptada el 15 de junio de 2000) que recoge la conveniencia de asegurar la totalidad de las rentas anteriores y aconseja una duración mínima de la prestación de maternidad de 18 semanas,

(10) Según datos de la EPA del primer cuatrimestre de 2017, el $96 \%$ de las personas que reducen su jornada laboral para dedicarse al cuidado de menores son mujeres. 
Probablemente ésta fue una de las razones, junto al compromiso adquirido con el gender mainstreaming, lo que impulsó la aprobación de la L.O.3/2007, de 22 de marzo, para la igualdad efectiva de mujeres y hombres, que modificaba la Ley de Conciliación - por cierto, posteriormente también retocada - nunca mejor dicho- por el Real Decreto Ley 3/2012, de 10 de febrero de Reforma Laboral. El objeto de la Ley de Igualdad queda recogido en su art. 1.1: "Las mujeres y los hombres son iguales en dignidad humana, e iguales en derechos y deberes. Esta Ley tiene por objeto hacer efectivo el derecho de igualdad de trato y de oportunidades entre mujeres y hombres, en particular mediante la eliminación de la discriminación de la mujer, sea cual fuese su circunstancia o condición, en cualesquiera de los ámbitos de vida y, singularmente, en las esferas política, civil, laboral, económica, social y cultural para, en el desarrollo de los artículos 9.2 y 14 de la Constitución, alcanzar una sociedad más democrática, más justa y más solidaria» y para ello establecerá - según especifica en su apartado $2 .^{\circ}-$ principios de actuación de los Poderes Públicos, regulando derechos y deberes de las personas físicas y jurídicas, tanto públicas como privadas, y preverá medidas destinadas a eliminar y corregir en los sectores público y privado, toda forma de discriminación por razón de sexo.

No obstante, la L.0.3/2007, de 22 de marzo, para la igualdad efectiva de mujeres y hombres, que nace con vocación de código de igualdad, y que enmarca - dentro del soft law - un conjunto de medidas para impulsar de manera fáctica la igualdad efectiva, no termina de conseguir los objetivos ambiciosos, necesarios y urgentes propuestos. Ello ha provocado que algunas voces apunten a la conveniencia de modificar nuevamente la ley por ineficiente; mientras que otras apuntan por perseguir la implementación de la misma y esperar a que el ordenamiento jurídico y político se empape del principio del gender mainstreaming y de la metodología de género incorporada al nuevo discurso normativo y político. Sea como fuere, el debate se encuentra en plena ebullición política y ciudadana y requiere de un compromiso social para evitar que esta previsible nueva apuesta legislativa o desarrollo reglamentario pueda seguir abandonando a las mujeres al albur de las necesidades reproductivas sociales o a los abusos patriarcales del sistema productivo.

Sin embargo, sorprende que pese a la urgencia de recuperar este tipo de análisis con perspectiva de género, éstos apenas aparezcan en los discursos dominantes. Si el conflicto de clases fue un elemento clave para entender la existencia del Estado Social o de Bienestar, lo cierto es que el Ilamado conflicto de Género, lo es para la comprensión de la Crisis Global. Se trata de la expresión más cruda de la crisis sistémica y global en la que estamos inmersos y que descansa, a su vez, en una crisis acumu- 
lada y multidimensional que afecta a la Sociedad delTrabajo y, como no a la crisis de los cuidados.

Pues bien, en nuestra línea de (re)pensar y sugerir medidas dirigidas a la eliminación de la discriminación y a la consecución del ejercicio de los derechos humanos y las libertades fundamentales para las mujeres sobre la base de la igualdad de mujeres y hombres, se nos plantea un enorme reto en el ámbito laboral: encontrar un modelo satisfactorio para mujeres y hombres coherente con las expectativas de la vida familiar y profesional, más aún ante las profundas transformaciones que están afectando al modo en que se relacionan éstos en dichos ámbitos. Ello exige la necesidad de modificar los términos y condiciones en que tienen lugar estas relaciones, a través de una puesta en común que conduzca a la redefinición de la correspondencia de tales espacios y tiempos de trabajo.

Dicho reto, nada fácil, requiere recuperar, en primer lugar, el panorama socio-laboral en el que las mujeres participan, así como mostrar, en segundo lugar, la situación en la que se encuentra nuestro Estado de Bienestar para conocer de manera directa cuáles van a ser algunos de los obstáculos o peligros que deberemos salvar en nuestra reflexión jurídicopolítica. No hacerlo así, esto es, no tener en cuenta la inversión de la pirámide demográfica, el descenso preocupante de la natalidad y el aumento de la tercera y cuarta edad, la crisis de acumulación, la crisis fiscal y de legitimación del Estado de Bienestar y la imposibilidad de prescindir de una mano de obra barata y auto-estimulada como es la femenina, supondrá volver a perpetrar una nueva violencia contra las mujeres, esta vez de la mano del Derecho y del Estado.

\section{Diagnóstico de la posición de las mujeres en la esfera laboral}

Siendo conscientes, como diría Alda Facio (Facio, 1993), que a veces, la preocupación -casi obsesiva - por justificar cada una de las aseveraciones - obvias - de la posición penalizada de las mujeres en el ámbito laboral, nos hace perdernos entre datos en demérito de la teoría, lo cierto es que en este momento sí parece conveniente partir de premisas derivadas de la diagnosis sociológica de la presencia ciudadana en el ámbito laboral, eso sí, con perspectiva de género. Estos son algunos datos(11) centrados en la realidad española, aun enmarcados en el contexto europeo:

a) En primer lugar, España posee una de las tasa de ocupación femenina más bajas de la Unión Europea, sólo por encima de Italia y

(11) A lo largo de este epígrafe se mencionan las distintas fuentes consultadas que incluyen, en su rastreo, todos los datos aportados. Se obvia aludir pormenorizadamente a cada una de ellas, para agilizar el texto en pro de una mejor lectura. 
Grecia. En este sentido, recientes informes(12) denuncian que ha aumentado la brecha de género en empleo, al reducirse - tras la crisis - en un 0,24\% y situarse en un $42,15 \%$ - más de 11 puntos por debajo de la tasa de empleo masculina. En lo que a la tasa de paro femenino se refiere, se ha incrementado en un $0,92 \%$, situándose en el $21,95 \%$, casi tres punto y medio $(3,43 \%)$ superior a la de los hombres, y erigiéndose en el segundo país de la Unión Europea con mayor índice de paro de mujeres. La tasa española de paro femenino se sitúa en el $25,4 \%$ frente a la europea que alcanza el $10,3 \%$. Triplica la tasa de paro de países como Finlandia o Suecia y llega a quintuplicar la de países como Alemania, Austria y Reino Unido. En conclusión: con datos comparativos de la EPA del segundo cuatrimestre de 2011 y de 2016, hay 63.000 ocupadas menos, el número de asalariadas se ha reducido en 117.400 mujeres y hay 105.400 mujeres más en paro. Los datos del Servicio Público de Empleo muestran una reducción del 1,32\% en la contratación femenina. Mientras que en julio de 2011 el porcentaje de mujeres contratadas se situaba en el $45,21 \%$, en el mismo mes de 2016 , éste ascendió a 43,89\%. Por lo tanto, la diferencia en el porcentaje de contratación a favor de los hombres es de $12,22 \%$ y el aumento de la brecha en esta materia una realidad.

b) En segundo lugar, las diferencias salariales entre mujeres y hombres con idénticos trabajos han aumentado en estos años de crisis, pese a los esfuerzos jurídicos antes mencionados. En España, según los datos de la última Encuesta Anual de Estructura Salarial publicada en 2015, la brecha salarial en 2015 alcanzó el 24\% cuando en 2011 la brecha se situaba en $22 \%$, lo que significa que las mujeres tendrían que trabajar 88 días más que los hombres para cobrar lo mismo. En su comparativa europea, la brecha salarial española supera en tres puntos a la comunitaria, con un $19,3 \%$ frente al $16,3 \%$, lo que se traduce en una diferencia de más de 6.000 euros en favor de los varones españoles. Esta diferencia se debe, en parte, a que las mujeres se concentran en los tramos de

(12) Informe de UGT de 8 de marzo de 2016 con motivo del Día Internacional de la Mujer Trabajadora. Accesible en internet. Expansión, sección economía, 11/09/2016. Asimismo, puede consultarse el Informe Brecha Salarial 2016, titulado "¿Por qué Carmen gana menos que Juan?", accesible en http://www.ugt-andalucia.com/document_library. Para la realización de este informe se han utilizado como fuentes de datos la Encuesta Anual de Estructura Salarial del Instituto Nacional de Estadística del año 2015, la Encuesta de población activa del IVTrimestre de 2015 y el Informe de Evaluación de Impacto de Género de Andalucía de 2016. Sorprendentemente la Encuesta Trimestral de Coste Laboral (INE) donde se recogen los datos más actuales, no incorpora datos desagregados por sexo. Recientemente acaban de publicarse los datos del Informe España, más cerca del Este de Europa, "La brecha salarial sectorial de la Unión Europea», de 3 de febrero de 2017, corroborando todas estas constantes aquí señaladas. 
salarios más bajos. De hecho, el $67 \%$ de los cerca de dos millones de personas trabajadoras que perciben salarios iguales o por debajo del SMI son mujeres, disminuyéndose su presencia conforme se incrementan los salarios. No obstante, no es esta la única razón. Los trabajos de las mujeres con estudios universitarios, sea cual sea su campo, también están peor remunerados. De este modo, quienes finalizaron el primer y segundo ciclo universitario en el curso 2009/10 sufren una diferencia de más de 2.000 euros anuales de sueldo respecto a los varones en 2011, diferencia que aumentó hasta los 2.900 euros en 2014(13).

c) En el panorama laboral siguen detectándose, pues, una segregación de oficios masculinos/femeninos, siendo las mujeres quienes ocupan puestos de inferior cualificación y poco prestigio social. Esto es así, pese a estar más presentes en todos los niveles de enseñanza no obligatoria, como Bachillerato, FP y Universidad, y pese a obtener mejores resultados académicos. La desigualdad entre hombres y mujeres se acentúa tras la ESO. Los datos desagregados por sexo detectan una mayor concentración de trabajo femenino en sectores donde la brecha salarial es muy acusada; a saber: sector servicios $(35,19 \%)$, el de actividades administrativas $(33 \%)$, los científicos $(30,73 \%)$ o el sector sanitario $(29,48 \%)$. Las mujeres se concentran en categorías profesionales poco cualificadas ( $80 \%$ de este sector está ocupado por mujeres) y soportan una brecha salarial del $30,4 \%$, lo que no necesariamente indica que no posean cualificación, sino que mujeres sobre-cualificadas se encuentran subpagadas.

d) Las mujeres siguen ocupándose de los trabajos dentro del hogar (domésticos, de cuidado y reproductivos), trabajos no remunerados ni reconocidos, pero necesarios más que nunca en una situación de crisis del Estado de Bienestar. La diferencia de trabajo realizado se calcula en 91 días más de trabajo no remunerado, lo que supondría que las mujeres en España trabajan un total de 179 días gratis (88 días de brecha salarial + trabajo no remunerado extra); esto es, casi la mitad de un año.

e) Por otra parte, el índice de empleo femenino a tiempo parcial en España quintuplica al masculino especialmente en lo tocante a quienes tienen descendencia. El $30 \%$ de las mujeres con hijos tienen un contrato a tiempo parcial, mientras que en el caso de los padres esta pro-

(13) Véanse los Datos y cifras del sistema universitario español recogidos en Datos y cifras del curso escolar 2016/2017 del Ministerio de Educación, Cultura y Deporte, 2016. Accesible en internet: www.mecd.gob.es 
porción ronda el $6 \%(14)$, y esta situación incorpora también parcialidad en los salarios, en las prestaciones sociales de jubilación y en las posibilidades de promoción o estabilización del empleo. Las mujeres representan, según datos de la EPA de enero de 2017, el 72,5\% de las personas ocupadas a tiempo parcial y no es por una cuestión de voluntas. Según UGT, el $60 \%$ de las mujeres que trabajan a tiempo parcial ha declarado no haber podido encontrar trabajo en jornada completa, lo que constata que no se trata de una libre elección de modalidad laboral de las mujeres, sino de una imposición-necesidad; al tiempo que la segunda de las razones - exclusiva de las mujeresdescansa en el cuidado de personas dependientes (menores o personas adultas enfermas, incapacitadas o menores en segundo grado de consanguinidad y/o afinidad). Y esta constante de asignación automática de trabajos a tiempo parcial para las mujeres también puede detectarse a nivel europeo: un 31,5\% de mujeres en la Unión Europea trabaja a tiempo parcial, frente al $8,3 \%$ de los hombres, siendo el $80 \%$ del total de empleo a tiempo parcial desempeñado únicamente que por mujeres. No es de extrañar, pues, que las mujeres en Europa ganen alrededor de un $17,1 \%$ menos por hora que sus compañeros varones y que haya tenido que instituirse simbólicamente el 22 de febrero como día europeo por la igualdad salarial.

f) Todo este panorama debe enmarcarse, a su vez, en el desequilibrio de uno de los pilares que sustenta el Estado de Bienestar. Ya no se encuentra compensado el relevo generacional. Por primera vez, en 2016, el número de óbitos supera al de nacimientos y no podemos desconocer la tendencia de esta dinámica uniformemente acelerada. España sobresale por su preocupante descenso del porcentaje de natalidad en los últimos treinta y cinco años, por debajo del nivel de reemplazo generacional, pasando de ser - en apenas unas décadas - de uno de los más altos de la Unión Europea (sólo superado por Irlanda) al más bajo. Si en 1975, el número medio de hijos/as por mujer era de 2,78, en el momento presente barajamos un tímido 1,32. Se requieren 260.000 nacimientos más al año(15), para poder compensar este decalage generacional, ahora enfati-

(14) Datos publicados por Eusrostat, newrelease, 45/2016, 7 march 2016. Este informe destaca el incremento de la brecha en contratos a tiempo parcial en mujeres madres, frente a padres con hijos. Asimismo denuncia la enorme brecha salarial - en detrimento de las mujeres trabajadoras - que en la Unión Europea asciende al $16 \%$.

(15) Datos pertenecientes al Informe de Evolución de la Familia en España, 2016, del Instituto de Política Familiar (IPF), presentados en Madrid, el 15 de mayo de 2017 con motivo del Día Internacional de la Familia. Curiosamente la previsión a la baja de estos datos fueron anunciados en el informe editado por la Consejería de Economía y Hacienda, a través del Instituto de Estadística de Andalucía, titulado Hogares y Familias en Andalucía. Evolución y proyección hasta 2016. 
zado por la superación del número de muertes frente al de nacimientos. Y esta situación crítica sólo ha sido comparable con la vivida en la I Guerra Mundial, tras la muerte de muchos hombres jóvenes y el retraso consecuente de la maternidad por la crisis económica de 1930. Junto a España, otros países del sur de Europa, como Grecia e Italia, siguen confirmando dicha dinámica: hasta una de cada 4 mujeres nacidas en 1970 podría no tener descendencia y la tendencia parece seguir in crescendo. Las mujeres son madres a partir de 32 años (frente a 1976 donde la edad elegida era la de 28,5 años), y algunas comunidades autónomas, como Asturias, Galicia o Canarias ya destacan por la correspondencia de menos de un hijo por mujer. Ya no tenemos recepción de inmigrantes para poder compensar este vacío y tampoco podemos desconocer la importante ratio de emigrantes - mujeres y hombres jóvenes - en busca de oportunidades laborales fuera de España.

g) Pese a ser el recurso humano más preparado, la mujer debe emplear más tiempo que un hombre para obtener un empleo. De hecho, casi un tercio de las mujeres necesitan más de un año para encontrarlo - siendo la media de 18 meses - , en tanto que la mayor parte de los hombres lo consigue en menos de seis meses. $Y$ aun cuando es conocido el dato de que las empresas con mujeres ejecutivas son más rentables, paradójicamente sólo un $3 \%$ las dirige.

h) Asimismo, el hecho de que la mayoría de las tareas domésticas permanezcan como responsabilidad de las mujeres y los servicios no respondan a la demanda, somete a las mujeres a un permanente estrés, que se traduce en rupturas en la trayectoria laboral, falta de productividad, ausentismo e inestabilidad de las trabajadoras encargadas de asumir las responsabilidades familiares. El retiro del mercado de trabajo en este caso, cualquiera que sea el momento, compromete a largo plazo los ingresos y la calificación necesaria para reincorporarse al mercado de trabajo. El $39 \%$ de las mujeres afirma haber renunciado a un empleo o ascenso laboral por tener hijos o personas a su cargo(16). Asimismo, el segundo trimestre de 2016 de la EPA muestra el preocupante número de mujeres (3.374.200) que aún permanecen inactivas por dedicarse al trabajo doméstico, frente a la inactividad en los hombres por esta razón que asciende a 383.300. Y es que son ellas las que renuncian a su carrera profesional ( 6 de cada 10 mujeres $(58,1 \%$ ) frente al $6,2 \%$ de abandono por parte de los hombres; -0 incluso creen,

(16) Estudio de la Fundación Pfizer "Conciliación y familia», junio de 2014. Accesible en http://www. fundacionfade.org/images/informe_final_estudio_foro_debate_social_2014.pdf 
aun antes de haberse generado esta necesidad- que serán ellas $(51,3 \%)$ las que tendrán que renunciar(17).

i) Como consecuencia de este doble trabajo, reproductivo (no remunerado ni reconocido) y productivo, que le obliga a tener que elegir entre "conciliar» o renunciar, (a costa de penalizaciones laborales y/o personales), su posición ante la vejez parte de una clara desventaja quedando su calidad de vida gravemente comprometida. Las mujeres en España(18) cobran casi un $40 \%$ menos de pensión que los hombres, situación especialmente preocupante en aquellas que pertenecen al grupo etario de 70 a 74 años. De este modo, frente a los 1.197,19 euros que viene a cobrar un pensionista, las mujeres sólo recibirán 742,81 euros. Hablamos de una diferencia nada desdeñable de 454,38 euros a favor de los varones que se incrementa en las pensiones por enfermedad, donde una mujer cobrará 535 euros menos que ellos. No olvidemos que sólo un $36,91 \%$ de las pensiones contributivas disfrutadas por mujeres son por jubilación(19). Además, las mujeres ponen rostro a la pensión no contributiva (el $70 \%$ de quienes las reciben son mujeres) y a la precariedad de las pensiones contributivas (el $70,71 \%$ de ellas se si-

(17) Datos pertenecientes al Estudio Somos equipo, de la asociación Yo no renuncio, presentados en marzo de 2017, y realizado a partir de 24.000 entrevistas a familias españolas en torno a las dificultades de conciliación de la vida familiar y laboral. Según la socióloga responsable de la investigación, Maite Egoscozabal, en atención a los resultados de la misma: «No es el factor económico el que justifica el reparto desigual de tareas, sino que esa desigualdad se debe a estructuras heredadas de una cultura patriarcal». Prueba de ello es que cuando las parejas aportan la misma cantidad de dinero al hogar, la mujer sigue siendo en el 45,2\% la principal responsable de las tareas doméstico-familiares, frente al $9 \%$ de los hombres.

(18) Con respecto a la brecha en pensión de jubilación por comunidades autónomas, Cataluña se presenta con una distancia superior $(37,15 \%=600$ euros menos) al de resto de comunidades como Extremadura (183 euros menos). No obstante, dicha diferencia no se debe tanto a cuestiones de igualdad, sino a que la cuantía media de la pensión de jubilación de los varones en dicha región es la más baja de España, ascendiendo a 975 euros. Ver informes de UGT antes referidos, especialmente el Informe España, Más cerca del Este de Europa, "La brecha salarial sectorial de la Unión Europea", 3 de febrero de 2017.

(19) Especialmente graves han sido los resultados de requerir período de carencia de 15 años para el acceso a la pensión de jubilación, asuntos resueltos por elTJUE, como es el Asunto Elbal Moreno, C-385/11- en Sentencia de 22 de noviembre de 2012. En el caso analizado la trabajadora, limpiadora de una comunidad de propietarios durante 18 años, en jornada parcial de 4 horas a la semana, debía cotizar 100 años para acceder a una ridícula pensión de jubilación de 112,93 euros al mes. Siguiendo las consignas del Tribunal Europeo, el TC falló en asunto similar (STC 61/2013, de 14 de marzo), declarando inconstitucional la regla 2 de la Disposición Adicional 7 de la LGSS, al vulnerar el artículo 14 de la Constitución española y generar una discriminación indirecta por razón de sexo y propició un cambio en la normativa española de la Seguridad Social por medio del RD Ley 11/2013, de 2 de agosto. Actualmente, las reglas específicas relativas a la acción protectora de la Seguridad Social, aplicables a los trabajadores a tiempo parcial se contemplan en los art. 245 a 249 de la TRLGSS, apostándose por el coeficiente de parcialidad acorde con la reducción proporcional de carencia según jornada trabajada respecto a un trabajador a tiempo completo. Al respecto de la sentencia delTC, véase Ron Latas, R.P., 2013. 
túan por debajo de 600 euros). Sin duda, todos estos datos analizados y desagregados por sexo, permiten poner rostro a la execrable "feminización de la pobreza».

\section{Austeridad y pacto europeo por la igualdad de género: áreas de intervención}

Las medidas jurídico-políticas adoptadas, especialmente durante estos años de crisis, no han ayudado, sino todo lo contrario, a conseguir mayores niveles de igualdad fáctica ciudadana. No en vano, las mujeres en España se han visto particularmente afectadas por la política de austeridad que ha recaído, muy especialmente, en recortes del sector público, en tanto que representan el $70 \%$ de la mano de obra en el sector. Asimismo, los recortes en la atención pública y los servicios de salud favorecen el retorno a los roles tradicionales de género. A nivel mundial, tal y como indica el Informe Global de la Brecha de Género publicado por el Foro Económico Mundial el 25 de octubre de 2016, serán necesarios 170 años (52 años más) para cerrar la brecha económica de género en el mundo, frente a los 118 años previstos en 2015.

Se requieren una red de servicios sociales solventes -también en nuestro sistema de Seguridad Social - para restringir las prácticas más informales de cuidado de las personas; se requiere apostar por la maternidad promoviendo y reconociendo el importante valor de la misma; se requiere una normativa laboral y no sólo laboral (no proteccionista, sino promotora) que reconozca a las mujeres como ciudadanas y no como "colectivo atípico" que demanda soluciones parcheadas... En definitiva, se reclama el enfoque transversal institucional que incorpore la perspectiva de género de manera principal (gender mainstreaming) y que destine sus recursos - humanos y económicos - a conseguir el objetivo último ratificado que es la igualdad efectiva ciudadana.

Pasemos a analizar desde una perspectiva de género algunas de las medidas arbitradas en tres ámbitos de intervención -desempleo y pobreza, trabajo de cuidados y violencia de género- y a desvelar el alarmante estado de desprotección de las mujeres, en tanto que ciudadanas, por parte del Estado español.

Recientemente, en febrero de 2015, el Comité Europeo de Derechos Sociales (CEDS) ha Ilamado la atención al Estado español por la disconformidad de la legislación interna laboral con los preceptos reconocidos en la Carta Social Europea (centrada en lo socio-laboral), durante el período de 1 de enero de 2009 a 31 de diciembre de 2012. La prueba de este corte transversal de la estructura sexo-género lo encontramos por ejemplo en las recientes medidas de reforma laboral adoptadas por el Go- 
bierno (Real Decreto-Ley 3/2012, de 10 de febrero), y convalidadas por el TC que, sin duda, repercuten duramente sobre las mujeres. $Y$ es que el aumento de la tasa de pérdidas (y/o precarización) de empleo femenino ha supuesto menor atractivo a su contratación; importantes recortes presupuestarios del sector público (como seguidamente constataremos); la Reforma de la Administración Local; y la consecuente intensificación por parte de las mujeres de tiempos y trabajos no remunerados en el seno del hogar (especialmente de las mujeres con rentas más bajas). Pese a la superación del trámite constitucional, esta reforma no supera el control de convencionalidad según el CEDS (Conclusiones XX-3 de 2014). Asimismo, el Comité Europeo refiere siete conclusiones de no conformidad con la Carta Social Europea que merecen ser mencionadas y observadas con la lupa metodológica del género.

Dichas conclusiones se refieren a: la insuficiencia del salario mínimo profesional; la flexibilidad de tiempo de trabajo; la compensación de las horas extraordinarias; las medidas compensatorias para personas trabajadoras expuestas a riesgos residuales para su salud; el período razonable de preaviso para la terminación del contrato, incluido el período de prueba en el contrato de apoyo a los emprendedores; la inaplicación unilateral del convenio colectivo; la injerencia del Gobierno en el ejercicio del derecho de huelga, a través del arbitraje obligatorio y la criminalización de la participación en huelgas.

Ya con anterioridad, el Comité Europeo de Derechos Sociales había señalado incumplimientos del Estado español (Conclusiones XX-2 (2013) en relación a los derechos del ámbito de la salud y la protección social (art. 3, 11, 12, 13, 14 de la CSE y art. 4 del Protocolo) con claras repercusiones de género, habida cuenta de la importante ratio de mujeres inmigrantes irregulares en nuestro país y de las dificultades de las mujeres para encontrar trabajo. En ellas se declaraba la disconformidad con la Carta Social Europea de las normas internas por las que se excluía del Sistema Nacional de Salud a las personas extranjeras por razón de su estatus irregular. Esta discriminación deriva del $R D$ 16/2012, de 20 de abril, de medidas urgentes para garantizar la sostenibilidad del Sistema Nacional de Salud y mejorar la calidad y seguridad de sus prestaciones y de la Ley 16/2003, de 28 de mayo, de cohesión de calidad del Sistema Nacional de Salud, y el $R D$ 12/2012, que requería para estar asegurado la residencia legal en España, lo que implicaría la exclusión de facto de la asistencia sanitaria de las personas extranjeras en situación irregular, pero también excluía a las personas de nacionalidad española de 25 años sin cotizaciones previas, la mayoría mujeres. Tampoco podemos olvidarnos de la especial vulnerabilidad de las mujeres inmigrantes - sin papeles- que, en el mejor de los casos, se dedican a empleadas de hogar y/o cuidado de 
personas dependientes, o a la prostitución o víctimas de mafias de trata de seres humanos.

El Comité Europeo de Derechos Sociales desecha en su último informe el argumento de la crisis como justificativo de restricciones legales en derechos sociales incluidos en la Carta Social Europea y que, por el contrario, deben ser "especialmente garantizados" en estos momentos.

Sin embargo, un inevitable análisis con perspectiva de género a los actuales Presupuestos Generales del Estado de 2016 nos permitirá concluir el abandono de la protección de los derechos de las mujeres como ciudadanas. Partamos de tres áreas de intervención, propias de los tres principales objetivos que se deben alcanzar según el Pacto Europeo por la Igualdad de Género (2011-2020), en el contexto de la Estrategia 2020, a saber: reducir las desigualdades en cuanto a empleo y protección social; promover un mejor equilibrio entre la vida laboral y privada de mujeres y hombres; y combatir todas las formas de violencia contra las mujeres.

\section{Desempleo y pobreza}

El Estado español, en estos años de crisis global, ha apostado por una política de recortes que, sin duda, repercute desde un análisis de género, directamente sobre las mujeres como ciudadanas. Algunas de estas medidas son: la incentivación de la contratación a tiempo parcial (modificando el régimen de las horas complementarias, para flexibilizarlo, o suprimiendo la preferencia de acceso a un puesto a tiempo completo); la congelación (o nula subida) del salario mínimo interprofesional; o los recortes en la Protección de desempleo: RAI, desvirtuándose el carácter asistencial de esta prestación; o el aplazamiento sine die de una mejora sustantiva de la pensión de viudedad. En este sentido, la reducción de un $22 \%$ de la partida de prestaciones ahondará la ya existente brecha de género $(22,55 \%$ o trabajar 82 días más al año que el varón y ser diplomada universitaria), habida cuenta de que las mujeres cuadruplican su presencia en trabajos a tiempo parcial y de corta temporalidad. Son empleos con pobreza e implican a su vez parcialidad salarial, de promoción profesional y de prestaciones sociales incluidas las de jubilación. En estos últimos cuatro años (2012-2015) la brecha entre la Tasa de paro de mujeres y hombres se ha triplicado. Asimismo, resulta obligado insistir en la omisión del análisis de género en los ingresos y Seguridad Social, cuando las pensiones contributivas y no contributivas vuelven a subir en 2016, el $0,5 \%$, y las pensiones de viudedad están en el centro del debate, siendo las mujeres el $93 \%$ de los 2,3 millones de personas que viven de ellas. En 
la actualidad, y tras estos años de crisis (20) y austericidio, la situación de las mujeres pensionistas se presenta peor y con mayor brecha de género que la existente en 2008.

Todo apunta a la necesidad de revisar el sistema de Seguridad Social, diseñado en su origen, en concordancia con el modelo laboral masculino, en donde el sustentador es el varón trabajador versus la esposa dependiente (que no sujeto), objeto de los derechos derivados. Las reglas del sistema retroalimentan esta desigualdad y empuja a las mujeres a la precariedad durante su vida laboral y a la dependencia económica durante el resto de su vida.

Asimismo, se ha reducido la financiación a los ayuntamientos - Ley 27/2013 de reforma de la Ley de Régimen Local - que deja sin recursos a los servicios sociales base, lo que desde una visión de género alerta del abandono de las mujeres y de su prole a la más absoluta pobreza. Es lo que se ha venido llamando feminización de la pobreza. Como muestra, un botón: el $72 \%$ de las personas beneficiarias del programa de solidaridad para personas con riesgo de exclusión social de la Junta de Andalucía, son mujeres.

\section{Trabajo de cuidados y conciliación}

El trabajo reproductivo (sin remuneración ni reconocimiento) sigue estando en manos de las mujeres lo que repercute, ineludiblemente, en las condiciones laborales, nivel de ocupación y tipo de empleo. Si a ello le sumamos la suspensión de la ampliación del permiso de paternidad hasta enero de 2017, la falta de dotación de escuelas infantiles de 0 a 3 años o la nimia subida en dependencia, destinada a disolverla (dentro y fuera de los domicilios), ineludiblemente el empuje y destierro de las mujeres al hogar es inevitable. En 2014 se tramitaron 31.435 excedencias por cuidado de hijo/as, de las cuales el $94 \%$ fueron tomadas por mujeres, porcentajes que se ha mantenido en 2015 (92\%). No olvidemos tampoco que el $97 \%$ de las personas que cuidan a personas dependientes son mujeres - tanto en el caso de las auxiliares de las residencias, como mujeres que se ocupan de ello dentro del hogar- y que 500.000 personas perdieron la ayuda a domicilio.

(20) Al iniciarse la crisis, entre las pensiones medias de uno y otro sexo había una diferencia del $28,7 \%$, manteniéndose prácticamente hasta 2011. En los dos años siguientes, inmersos en ella, la brecha se abrió abruptamente elevándose al $29,6 \%$ en 2012 y al 32,6\% en 2013. En la actualidad, pese a la leve recuperación, no ha sido posible compensar el decalage entre pensiones. Datos recogidos recientemente por Clavero, 2017. 
Si a ello le sumamos que España sólo destina a las familias el 1,31\% del PIB, frente al 2,2\% de media europea (21), y que las prestaciones familiares españolas apenas suponen el $59 \%$ de la comunitaria, entenderemos la falta de compromiso político y la dejación de responsabilidades reproductivas en las espaldas de las mujeres.

$Y$ es que las últimas modificaciones acometidas por la Reforma Laboral(22) de 2010 y 2012 han considerado el derecho a la conciliación como un espacio más, susceptible de recortes flexibilizadores unidireccionales (en interés de la empresa) y no como un ámbito que requiere especial protección (23), tal y como exige la Ley de Igualdad y la normativa comunitaria. Algunos ejemplos de esta política de «reprivatización de la reproducción social" son: el cambio en el alcance del derecho subjetivo a la lactancia; la reformulación del alcance de las reducciones de jornada (Pazos Pérez, 2012: 242 y ss ) por cuidado de menores o familiares (cómputo diario); el debilitamiento de la negociación colectiva y el empoderamiento de los criterios establecidos por Convenio Colectivo para la concreción horaria de la reducción de jornada por cuidado (art. 37.6 E.T.) y la distribución irregular del $10 \%$ de la jornada de trabajo (art. 34 E.T); la desaparición de las bonificaciones establecidas en el art. 4.2 de la Ley 43/2006, para facilitar la reincorporación de la mujer trabajadora tras la maternidad o la excedencia por cuidado de hija/os; o las modificaciones en la movilidad geográfica (art. 40 E.T.) y modificación sustancial de condiciones de trabajo (art. 41 E.T.).

\section{Violencia de género en el contexto de pareja}

Los PGE han aumentado en un $6,3 \%$ los recursos destinados a violencia de género en el contexto de pareja, pero siguen estando por debajo de los niveles de 2009 (baja el 10,92\%), resultando claramente insuficientes para afrontar esta lacra social. Con la crisis, en apenas tres años, se han reducido en $30 \%$ los fondos para prevenir la Violencia. Ya en 2015 se pretendió corregir la cifra incrementando un $8.6 \%$ estas partidas (aumentando la partida de Igualdad Efectiva a 20,82 millones y 23,7 millones la

(21) Frente a España y superando la media europea, nos encontramos con países con una inversión significativa del PIB en las familias; a saber: Dinamarca invierte el 4,1\% del PIB, Luxemburgo el 3,6\% e Irlanda el $3,4 \%$, lo que repercute en un aumento de la natalidad y en la consecuente mejora de la calidad de vida de los miembros que conforman la unidad familiar.

(22) Esta gran Reforma se ha instrumentalizado a través del Real Decreto Ley 10/2010, de 16 de junio, de medidas urgentes para la reforma del mercado de trabajo, de la Ley 35/2010, de 17 de septiembre, de igual título, del Real Decreto Ley 3/2012, de 10 de febrero, de medidas urgentes para la reforma del mercado laboral y de la Ley 3/2012, de 6 de julio, de igual título.

(23) Al respecto, merece la pena la lectura de Ballester, 2012: 99-100. Asimismo, véanse las siempre interesantes aportaciones de Lousada Arochena, 2013. 
de Violencia de Género), pero esto supone, en conjunto el 0,01\% del presupuesto total, además de ser una cantidad insuficiente para suplir el recorte de los Ayuntamientos antes referido. Esto ha supuesto el cierre de casas de acogida, Centros de la Mujer y la destrucción de 5.000 puestos de trabajo (Gil Ruiz, 2014: 11).

Por supuesto, mucho hay que decir sobre la escasez de recursos para formación en género, exclusión en los curricula de asignaturas formativas al respecto (Gil Ruiz, 2014b y 2015), y centralización del enfoque de la violencia en el plano penal (aun deficitaria) en detrimento de la igualdad y del consecuente recorte en medidas educativas, preventivas y sociales. Un dato más de la confluencia de factores discriminatorios en las mujeres lo constata además el nada desdeñable incremento de la violencia de un $33 \%$ en las mujeres con discapacidad.

\section{Algunas propuestas concluyentes y de mejora}

Acorde con el Plan Estratégico de Igualdad de Oportunidades (20142016), destacan dos objetivos - aún caballos de batalla- de especial relevancia para fomentar la igualdad de género en materia de empleo: la lucha contra la discriminación salarial (eje 1) y la conciliación de la vida personal, familiar y laboral, junto a la corresponsabilidad en la asunción de las responsabilidades familiares (eje 2). Sin duda, la necesidad de resaltar y promover el trabajo (en sentido amplio) de las mujeres, sus aptitudes y destrezas, se erige como pieza clave para combatir la brecha de género que, sin duda, también afectará a la clasificación, valoración y promoción profesional.

En tanto que de la resolución de dichos problemas, sin duda, van de la mano, se hace necesario que las relaciones entre el mundo laboral, la esfera doméstica, el Estado y las necesidades sociales, sean transformadas. $Y$ ello es así porque de su superación depende tanto la reproducción social, como el logro de la igualdad material ciudadana. Se exige la corresponsabilidad individual y colectiva, pero también se requiere que las organizaciones, agentes y también instituciones se impliquen en reformular los tiempos y experiencias de la vida de mujeres y hombres, al unísono con lo dispuesto en la Estrategia Europa 2020 y en las Directrices integradas para las políticas económicas de los Estados miembros (2010-2014)(24). Todas

(24) Debe destacarse la Directriz 7. ${ }^{a}$ de las Directrices integradas en la Recomendación del Consejo de 27.4.2010 SEC (2010) 488 final que establece: «(...) Las medidas de conciliación de la vida personal y la vida laboral deberán conjugarse con la oferta de servicios asequibles y con innovaciones en la organización del trabajo a fin de aumentar los índices de empleo, especialmente entre los jóvenes, los trabajadores de mayor edad y las mujeres, procurando que las mujeres altamente cualificadas en los ámbitos técnicos y científico no abandones sus empleos». 
estas constantes hemos de tenerlas muy presentes en un contexto de crisis del Estado de Bienestar como el que estamos padeciendo y que se manifiesta con características claras y alarmantes a corto-medio plazo: Inversión de la pirámide demográfica (descenso drástico de la natalidad e incremento de la $3 .^{a}$ y $4 .^{a}$ edad a la que habrá que cuidar); necesidad urgente de reducir gasto público; imposibilidad de prescindir de una mano de obra barata y autoestimulada como es la femenina; e impacto de la 4. ${ }^{\text {a }}$ Revolución Industrial centrada en la robotización y donde las mujeres se encuentran muy mal posicionadas. He aquí algunas de nuestras propuestas de cambio, - no exclusivas sino aproximativas - , centradas, en buena medida, en recuperar el derecho de conciliación como lo que debe ser: un ámbito que requiere de especial protección y promoción(25) y que no es susceptible de recortes ni postergaciones.

1. Conformación de una normativa laboral, tanto legal como convencional, que incorpore una perspectiva de género de manera principal y transversal (que supere la tradicional visión masculina y patriarcal). Ello permitirá transcender la configuración de las mujeres como anejos en el ámbito laboral - trabajador atípico- que parece prestar sus servicios a tiempo parcial o con temporalidad.

2. Necesidad de revisar el sistema de Seguridad Social, gestado en un marco de relaciones de trabajo desfasado, pensado en el varón como sustentador de la economía familiar frente a la mujer, esposa - centrada en las tareas de cuidado- y dependiente de sus derechos sociales. Actualmente, el déficit de integración de las mujeres en el mercado laboral - siendo el recurso humano más preparado-, genera un déficit de eficacia, pero también un déficit de equidad. Las desigualdades inter géneros se perpetúan, pero también se retroalimentan, ampliándolas.

3. Necesidad de valorar y reconocer las destrezas y aptitudes de las mujeres, así como su responsabilidad, esfuerzo y condiciones de trabajo(26), para subvertir la escala de valoración de factores en los procedimientos cuantitativos (y cualitativos) como técnica de recursos humanos. La constante sobreponderación de los méritos patriarcales (centrados en cuestiones «económicas»), frente a la subestimación de los méritos tradicionalmente considerados femeninos (precisión, destreza, coordinación manual), sigue colocando

\footnotetext{
(25) Este enfoque es el exigido tanto en L.0.3/2007, de 22 de marzo para la Igualdad efectiva de Mujeres y Hombres, en la jurisprudencia reciente delTC (STC 26/2011), así como en la normativa comunitaria ya referida.

(26) Al respecto, véase la Directiva 2006/53/CE y el trabajo de los servicios de la Comisión que acompaña al informe sobre su aplicación, así como la Guía «Promoción de la Igualdad salarial por medio de la evaluación no sexista de los empleos», publicada por la OIT en 2008.
} 
a las mujeres en subsectores productivos - poco reconocidos $\mathrm{ni}$ valorados - continuadores de las tradicionales funciones asignadas en el ámbito doméstico.

4. Actuar en educación y concienciación social que debe insistir en la necesidad de apostar por otro modelo de mujer, no lastrado ni hipotecado, dependiente de la dependencia de los demás (esposo+prole+progenitores). Asimismo debe enseñarse la importancia del cuidado (propio y ajeno), y reconocer, en tanto que responsabilidad social (art. 14.7 de la LOIEMH) y colectiva (que no problema individual de las mujeres), la ineludible tarea de conciliación de la vida familiar, laboral y personal, enfocada hacia la corresponsabilidad. Se trata de una cuestión estructural que reclama cambios (Marrades, 2016), aún hoy, no resueltos y que reatraviesa la economía, la política, la cultura, la ética, y por supuesto, el Derecho.

5. Reconocimiento y promoción de la maternidad, en tanto que generadora de bienes sociales y evitar cualquier hermanamiento -formal o informal - con la enfermedad. En este sentido, deben repensarse los permisos de maternidad y paternidad (art. 44 de la LOIEMH) -que han de ser ante todo y sobre todo, intransferibles - . Asimismo debe garantizarse de manera absoluta el retorno al empleo tras el disfrute de cualquier permiso parental y apostar por una política de incentivos al empresariado (ahora eliminados(27)) para compensar cualquier desequilibrio al respecto. En esta línea, el proyecto de Ley de Presupuestos Generales del Estado de 2017 añade la disposición adicional obligatoria que confirma la necesidad de incluir una bonificación (50\% en sus aportaciones a la Seguridad Social) para aquellas empresas que destinen a sus trabajadoras embarazadas - con riesgo en el embarazo o durante la lactancia natural - a otro puesto de trabajo o función específica compatible con su estado.

6. Revisión del concepto de flexibilidad del tiempo de trabajo - actualmente unidireccional, en el sentido de adaptación a las necesidades productivas de las empresas - en atención a las necesidades vitales de las personas. Esta prioridad a las necesidades de las empresas, reforzada tras la última reforma laboral por Real Decreto Ley 16/2013, de 20 de diciembre, de medidas para favorecer la contratación estable y mejorar la empleabilidad de las personas traba-

(27) La disposición derogatoria única, apartado 1, letra f), de la Ley 3/2012, de 6 de julio, deroga el artículo 4.2 de la Ley 43/2006, de 29 de diciembre, para la mejora del crecimiento y del empleo, que regulaba las bonificaciones en las cotizaciones por reingreso tras la maternidad o excedencia por causa de conciliación. 
jadoras, no sólo afecta a la "penalizada" reducción de jornada por cuidado de personas enfermas, sino también al impulso de los contratos a tiempo parcial, en detrimento de las mujeres, en tanto que sujeto directamente afectado. Se requiere su urgente revisión y el consecuente impulso a la conciliación de la vida personal, familiar y laboral, (aún más) lastrado tras la posibilidad de horas complementarias "de aceptación voluntaria», así como el establecimiento de la reducción de la jornada con márgenes más abiertos y flexibles, tanto en la reducción mínima como en la máxima, mirando - esta vez- a los ojos de la ciudadanía.

7. Apuesta por una red de servicios sociales solventes para restringir las prácticas más informales de cuidado de las personas (problema a corto-medio plazo con la inversión de la pirámide demográfica y aumento de la tercera y cuarta edad).

8. Impulso de prestaciones(28) y subsidios familiares solventes que constituyan un entramado potente de prestaciones de Seguridad Social; a saber: subsidio parental de educación, subsidio por hijo/ as de corta edad, ayuda al empleo de cuidado de cuidado de niño/ as (tanto por lo que se refiere al salario como a las cotizaciones sociales), subsidio para el cuidado de niño/as a domicilio (especialmente recomendable para progenitores con horarios penalizados) y potenciación del sistema de guarderías (gratuitas y de calidad). Estas medidas han supuesto que en Francia, el $85,4 \%$ de las madres con un vástago de menos de seis años esté trabajando. Asimismo, se deberían arbitrar subsidios pensados para paliar la urgencia y requerimiento de cuidados para la tercera y cuarta edad.

9. Flexibilizar el trabajo remunerado (supresión de la ausencia de horarios, especialmente para las personas trabajadoras de grupos superiores). Se pretende desviar el criterio de valoración de los cuadros desde la tradicional disponibilidad hacia su eficacia.

10. Mejorar y potenciar la promoción laboral de las mujeres tanto en el ámbito privado como público o semi-público. Algunos datos reclaman dicha medida. Con respecto al primero - el ámbito privadode 2015 a 2016, el porcentaje de mujeres directivas en los Consejos de Administración del Ibex subió apenas del 13\% al $20 \%$. En 2017 (29) el incremento ha sido de un esquelético $1,1 \%$ lo que co-

(28) Durante la presentación del proyecto de los Presupuestos Generales de 2017, el Gobierno ha confirmado la previsión de un incremento del $11 \%$ del gasto de 2017 para el conjunto de prestaciones que aparecen vinculadas a la cesación temporal en el trabajo por nacimiento de hijo, maternidad, paternidad, riesgo durante el embarazo y riesgo durante la lactancia con una dotación de 2.450 millones de euros.

(29) Informe IESE Business School y Atrevia, sobre la presencia de las mujeres en la dirección de las grandes empresas españolas, 2017. 
rrobora una evidente ralentización con respecto al año anterior. En relación al segundo - el ámbito público o semi-público- la RAE es un buen ejemplo de cómo urgen medidas de acción positiva diferenciadora. De casi un total de 500 miembros que han ostentado un lugar en la Academia a lo largo de su historia, sólo 11 han sido mujeres y ninguna ha sido directora. En la actualidad sólo hay 8 de 44 miembros, lo que apenas alcanza un $18 \%$ de presencia de mujeres como ciudadanas en el espacio de la palabra(30). Este anacronismo permanente $\mathrm{y}$ enquistado probablemente justifique la activación de medidas de acción positiva diferenciadora previstas (art. 11 de la LOIEMH) para motivar cambios en cumplimiento de objetivos previos marcados, en sectores reticentes (31).

11. Impulsar el emprendimiento femenino (En el 2012 se calculaba que un $4 \%$ de las mujeres locales había iniciado una actividad por cuenta propia. Tres años más tarde esa cifra aumentó únicamente hasta el 5,4\%).

12. Persecución de la obligación general (art. 14 de la Constitución y art. 17.1 ET) y del mandato específico a las empresas, previsto en nuestra legislación laboral (art. $85.1 \mathrm{ET}$, art. 45 y 46 de la LOIEMH), de actuar para evitar situaciones de discriminación y negociar medidas para promover la igualdad de trato y de oportunidades entre mujeres y hombres en el ámbito laboral. Cierto es que ateniéndo-

(30) Probablemente la activación de este tipo de medidas de acción positiva diferenciadora que permitiera el acceso de las mujeres - en tanto que mitad de la población - a ámbitos patriarcales muy marcados como es la RAE lograría el avance de medidas jurídicas - por otra parte, impulsadas desde la Unión Europea - como es el uso inclusivo y no sexista del lenguaje en el ámbito administrativo, pero también en la totalidad de las relaciones sociales, culturales y artísticas (art. 14.11 LOIEMH). Asimismo, podrían minimizarse las reticencias existentes por parte de algunos académicos para colaborar con el mandato jurídico de representación ciudadana. Sirvan las palabras de Arturo Pérez Reverte, académico de la RAE, al respecto, recogidas en su artículo "No siempre limpia y da esplendor", y publicadas en su sección Patentes de Corso en XL Semanal, de 3 de octubre de 2016: «Y es que, como dije antes, en la RAE hay de todo. Gente noble y valiente y gente que no lo es. Académicos hombres y mujeres de altísimo nivel, y también, como en todas partes, algún tonto del ciruelo y alguna talibancita tonta de la pepitilla. En Felipe IV sigue cumpliéndose aquel viejo dicho; hay académicos que dan lustre a la RAE, y otros a los que la RAE da lustre. Que acabaron ahí por carambolas, cuotas o azares, y deben a la Academia buena parte de lo que son, o aparentan ser, ahora». Estas palabras del "alatristemente célebre productor de best sellers» fueron replicadas por el también académico Francisco Rico, en su artículo "Las académicas y los académicos» en la sección Opinión del diario EL PAÍS, de 14 de octubre de 2016.

(31) Este tipo de medidas - temporales, razonables y proporcionadas - podrían corregir situaciones patentes de desigualdad de hecho respecto de los hombres; a saber: infrarrepresentación de mujeres en Cátedras, Investigadoras Principales en Proyectos Competitivos, Altos Tribunales (TC, TS, Presidencia de Tribunales), Reales Academias, entre un largo etcétera que incluye la infarrepresentación de mujeres en sectores tradicionalmente considerados como masculinos. En esta línea, el Ayuntamiento de Valencia ha previsto la modificación de su Plan de Igualdad para 2017 contemplando acciones positivas para la contratación de mujeres en los puestos de trabajo municipales donde se encuentren infrarrepresentadas, como los de Policía Local y Bomberos, y cuya presencia se eleva apenas a un 12,3\% de la plantilla, en el conjunto del área de Protección Ciudadana. 
nos a la literalidad de la ley (art. 85.1 ET), ésta repara en el «deber de negociar» pero no en la "obligación de llegar a acuerdos». En la necesidad de fiscalizar que los mandatos jurídicos se cumplan, urge el empoderamiento de los Servicios de Inspección Laboral. La urgencia de evaluar (para evitar su devaluación) la elaboración, ejecución y seguimiento de los Planes de Igualdad de la Empresas obligadas a incorporarlos en su acervo normativo, así como activar una política eficaz de sanciones, en caso de incumplimiento, permitiría acortar la brecha de género (salarial, de promoción y condiciones de trabajo) de cada una de éstas.

13. Relanzar el distintivo de excelencia "lgualdad en la empresa" para premiar las buenas prácticas y los cambios a través del carácter persuasivo (que no solo sancionador) de las medidas jurídicas y políticas arbitradas. Ello facultaría para fomentar en la pequeña y mediana empresa (99.84\% de nuestro actual tejido empresarial (32), descontando autónomos) la conveniencia de apostar por la igualdad efectiva ciudadana porque es - aparte de una cuestión de justicia social-, sencillamente, una buena oportunidad para su empresa.

Éstas son sólo algunas de nuestras propuestas, conscientes de las muchas que quedan en el tintero, y de la importancia de apostar, además, por un nuevo modelo de socialización diferencial que no impulse la asignación - predestinada y subordinada - de esferas (domésticaprivada y pública) ni la imposibilidad de saltar de una a otra, sin abandonos ni penalizaciones. No sólo las instancias productivas (mercado y propiedad), y las formales-representativas (procesos judiciales y parlamentos) forman parte del «sistema público de reglas que definen cargos y posiciones con sus derechos y deberes, poderes e inmunidades" (Rawls, 1993: 76). Sabemos de la importancia de la asignación "encubierta» de papeles desde las instituciones socializadoras, asignando una definición social de los sexos.

Sólo redenifiniendo el modelo de ciudadanía(33) - completa y compleja- y apostando por el paradigma de justicia del "reconocimiento" que parte del «fundamento de que los demás son como uno mismo y que

(32) Según datos proporcionados por el Ministerio de Empleo y Seguridad Social, correspondientes a enero de 2017, de un total de 2.839.112 empresas, 4262 corresponden a empresas de más de 250 personas trabajadoras.

(33) A nivel comunitario, BARRÈRE UNZUETA (2003: 47-66) ya lamentó la oportunidad perdida de refundar el concepto de ciudadanía europea tanto por el Tratado de Maastricht de 1992 como por las modificaciones introducidas en Ámsterdam e insistió en la importancia de elaborar un concepto europeo de ciudadanía basado en la igualdad de género. Especialmente interesante resulta su aportación desde la perspectiva iusfeminista en su libro El Derecho Antidiscriminatorio y sus límites (2014). 
nada que uno se conceda a sí mismo tiene derecho moral a no concedérselo a otro, sino que, al contrario tiene el deber de pensar en el otro como en un sí mismo" (Valcárcel, 1993: 7), conseguiremos un modelo de Estado y de democracia que afronte y resuelva el dualismo vital y extinga, por fin, la brecha ciudadana.

\section{Bibliografía}

BARRÈRE UNZUETA, M.A. (2003), "Ciudadanía europea e igualdad de género", Revista Vasca de Administración Pública, n. ${ }^{\circ}$ 66, pp. 47-66.

BARRÈRE UNZUETA, M.A. (2014), El Derecho Antidiscriminatorio y sus límites, Grijley, Perú, 2014.

BALLESTER PASTOR, M.A (2012), «De cómo la reforma operada por el Real Decreto Ley $3 / 2012$ ha degradado el derecho fundamental a la conciliación de responsabilidades", Revista de Derecho Social, n. ${ }^{\circ}$ 57, pp. 99 y ss.

CABEZA PEREIRO, J. (2012), "La discriminación retributiva por razón de sexo como paradigma de discriminación sistémica», Lan Harremanak/ Revista de Relaciones Laborales, n. ${ }^{\circ} 25$.

CASTAÑO, C. (dir.) (2015), Las mujeres en la gran recesión: políticas de austeridad, reformas estructurales y retrocesos en la Igualdad de Oportunidades, Valencia: Cátedra, Colección Feminismos.

CLAVERO, V. (2017), "Desigualdad. La brecha entre las pensiones de hombres y mujeres se ha ensanchado durante la crisis», PUBLICO, 8 de febrero de 2017.

FACIO MONTEJO, A. (1993), Cuando el Género suena, cambios trae. Una metología para el análisis del fenómeno jurídico desde la perspectiva de Género, Illanud.

FERNÁNDEZ PRIETO, M. y CABEZA PEREIRO, J. (ed.) (2012), Políticas de conciliación, permisos parentales y empleo, Albacete: Bomarzo.

GIL RUIZ, J.M. (2012), Las nuevas Técnicas Legislativas en España, Valencia:Tirant lo Blanch.

GIL RUIZ, J.M. (2014a), "La Violencia Institucional de Género», Anales de la Cátedra Francisco Suárez, n. ${ }^{\circ} 48$, pp. 9-18.

GIL RUIZ, J.M. (2014b), "Introducción de la perspectiva de género en las Titulaciones Jurídicas: hacia una formación reglada», en Revista de Educación y Derecho. Education and Law Review, vol. 10.

GIL RUIZ, J.M. (2015), «Formación en Derecho Antidiscriminatorio: carencias e incumplimientos institucionales", Revista ACADEMIA. Revista sobre enseñanza en Derecho, vol. 26, año 13, Argentina, pp. 49-77.

GIL RUIZ, J.M. (2017), «En torno al artículo 14 de la CEDJ: Concepto, jurisprudencia y nuevos desafíos de (y ante) el Consejo de Europa», en 
Revista Quaestio luris, Vol. 10, n. ${ }^{\circ}$ 02, Río de Janeiro, pp. 919-954. DOI: 10.12957/rqi.201727702.

GIL RUIZ, J.M. (2017), «Towards a modern antidiscrimination Law», en European Law Journal (en revisión).

LOUSADA AROCHENA, J.F. (2013), "La reforma laboral en perspectiva de género", XIV Congreso Nacional de Abogados Laboralistas, organizado por la Asociación Nacional de Abogados Laboralistas, A Coruña.

MARRADES, A. (2016), "Los nuevos derechos sociales: el derecho al cuidado como fundamento del Pacto Social», en UNED. Revista de Derecho Político, n. ${ }^{\circ}$ 97, pp. 209-242.

PAZOS PÉREZ, A. (2012), "La reducción de jornada tras las últimas reformas legislativas", en FERNÁNDEZ PRIETO, M. y CABEZA PEREIRO, J. (ed.), Políticas de conciliación, permisos parentales y empleo, Albacete: Bomarzo, pp. 242 y ss.

RAWLS, J. (1993), Teoría de la Justicia, Madrid: FCE.

REY-MARTÍNEZ, F. (2004), "Comentario a los informes del Consejo de Estado sobre el impacto por razón de género», Teoría y realidad constitucional, n. ${ }^{\circ} 14$, pp. 500-523.

RON LATAS, R.P. (2013), "Comentario a la Sentencia del Tribunal Constitucional 61/2013, de 14 de marzo, sobre la cuestión de constitucionalidad sobre pensiones de jubilación para trabajadores a tiempo parcial», $R e$ vista Aequalitas, n. ${ }^{\circ} 32$.

VALCÁRCEL, A. (1993), Del miedo a la igualdad, Barcelona: Crítica.

Trabajo recibido el 9 de junio de 2017

Aceptado por el Consejo de Redacción el 20 de octubre de 2017 
LABURPENA: Klaseen gatazka elementu giltzarria izan zen aurreko mendeko estatu soziala edo ongizate-estatua ulertzeko; xxI. mendeko mundu mailako krisia ulertzeko, ordea, genero-gatazka deiturikoa da elementu giltzarria, eta, zalantzarik gabe, aro berri honetako erronkak ezaugarritzen ditu. Artikulu honek bere egiten du genero-metodologia, eta, Europako nahiz estatuko araudiaren bilakaera-testuinguruan eta emakumeek lan-eremuan duten kokalekuaren diagnostikotik abiatuta, Espainiak ongizate-estatuaren krisiaren aurrean emandako erantzuna eta emakumeek hiritar diren heinean duten babesgabetasuna jorratzen dira. Era berean, hobetzeari begirako proposamen juridiko-politiko batzuk aurreratuko dira, ongizate-estatuaren egungo desoreketatik abiatuta, epe labur-ertainean herritarren gainera eroriko diren arrisku batzuk ahaztu gabe. Lege ferenda-ko proposamen horiek - ez esklusiboak, gutxi gorabeherakoak baizik-, bizi-dualismoa eta herritarren banaketa konpontzeari begirakoak, hein handi batean zentratuko dira kontziliazio-eskubidea berreskuratzeko arloan, kontziliazio-eskubide horrek izan behar duen horretatik abiatuta: babes eta sustapen berezia behar dituen eremua da, murrizketarik edo luzamendurik onartzen ez duena.

GAKO HITZAK: Ongizate-estatuaren krisia. Herritarren banaketa. Lan-merkatua. Lan-eskubideak. Gizarte-prestazioak. Erantzunkidetasuna. Egiturazko berdintasunik eza. Gender mainstreaming. Aurrekontu-murrizketak. Herritarrak.

RESUMEN: Si el conflicto de clases fue un elemento clave para entender la existencia del Estado Social o de Bienestar en el siglo pasado, lo cierto es que el llamado conflicto de Género, lo es para la comprensión de la Crisis Global del siglo XXI y enmarca, sin duda, los nuevos desafíos de esta nueva era. Este artículo hace suyo la metodología de género y aborda - en un contexto de evolución normativa europea y nacional y partiendo del diagnóstico de la posición de las mujeres en la esfera laboral-, la respuesta española ante la crisis del Estado de Bienestar y la desprotección de éstas en tanto que ciudadanas. Asimismo, se avanzarán algunas propuestas jurídico-políticas concluyentes y de mejora, partiendo de los desequilibrios actuales del Estado de Bienestar, sin obviar algunos de los peligros que se ciernen a corto-medio plazo sobre la ciudadanía. Estas propuestas de lege ferenda - no exclusivas sino aproximativas - dirigidas a resolver el dualismo vital y la brecha ciudadana, se centrarán en buena medida, en recuperar el derecho de conciliación como lo que debe ser: un ámbito que requiere de especial protección y promoción y que no es susceptible de recortes ni postergaciones.

PALABRAS CLAVE: Crisis del Estado de Bienestar. Brecha ciudadana. Mercado laboral. Derechos laborales. Prestaciones sociales. Corresponsabilidad. Desigualdad estructural. Gender mainstreaming. Recortes presupuestarios. Ciudadanía.

ABSTRACT: If the Class conflict was key for the understanding of the welfare state in the last century, the so-called Gender conflict has become fundamental for a similar understanding of the $21^{\text {st }}$ century Global Crisis and its challenging consequences. This article supports the gender methodology and addresses -in 
the context of the evolution of national and European legislations on the basis of the women status in the labour market-, the Spanish response to the crisis of the welfare state and the lack of protection of women as citizens. In addition, insofar Spain must respond to the commitments made to Europe regarding the public agenda, some conclusive legal and political proposals and improvements will be made in this paper, based on the current imbalances of the welfare state, without neglecting some of the dangers in the short-medium term of the citizenship. These lege ferenda proposals - not comprehensive but rather approximate - are aimed at resolving the vital dualism and the citizenship gap. They will focus, to a great extent, on recovering the right of conciliation as what it should be: an area that requires special protection and promotion and which is not susceptible to cuts or any further delays.

KEYWORDS: Welfare state crisis. Citizenship gap. Labour market. Labour rights. Social benefits. Joint responsibility. Structural inequality. Gender mainstreaming. Budget cuts. Citizenship. 